\title{
Swine virus-specific cytotoxic cells producing IFN $\gamma$ under different conditions of virus antigenic stimulation
}

\author{
L. Ferrari • E. De Angelis • P. Martelli • P. Borghetti
}

Published online: 30 May 2010

(C) Springer Science+Business Media B.V. 2010

\begin{abstract}
Flow cytometry is a useful tool to determine both the phenotype and function of immune cells during vaccination and viral infection. Since cytokine release is a hallmark of cell activation, detection of intracellular interferon (IFN) $\gamma$ in cytotoxic CD $8 \alpha+$ cells under physiological conditions and after Aujeszky's Disease Virus (ADV)- or Porcine Circovirus type 2 (PCV2)-swine interaction was carried out. Blood samples were collected from healthy 10-month-old pigs, ADV- or PCV2-vaccinated pigs, and PCV2-infected pigs; the levels of total IFN $\gamma+$ and $\mathrm{CD} 8 \alpha+\mathrm{IFN} \gamma+$ cells were evaluated after PMA-ionomycin and virusspecific in vitro stimulation. High $\mathrm{CD} 8 \alpha+\mathrm{IFN} \gamma+$ cell levels were detected in adult pigs, whereas lower virus-specific cell fractions were observed after ADV or PCV2 vaccination as well as after PCV2 natural infection due to restricted activation. Such results support the use of cytokine intracellular staining to monitor virus-specific cell-mediated immunity.
\end{abstract}

Keywords Swine $\cdot$ Cell-mediated immunity $\cdot \operatorname{IFN} \gamma \cdot \mathrm{ADV} \cdot \mathrm{PCV} 2$

$\begin{array}{ll}\text { Abbreviations } \\ \text { ADV } & \text { Aujeszky's Disease Virus } \\ \text { PCV2 } & \text { Porcine Circovirus type 2 } \\ \text { gE- } & \text { Glycoprotein E negative } \\ \text { TK- } & \text { Thymidine Kinase negative } \\ \text { MLV } & \text { Modified-Live Virus } \\ \text { PCVD } & \text { Porcine Circovirus Associated Disease } \\ \text { PBMC } & \text { Peripheral Blood Mononuclear Cells } \\ \text { MOI } & \text { Multiplicity Of Infection } \\ \text { IFN } \gamma & \text { Interferon- } \gamma \\ \text { CD } & \text { Cluster of Differentiation }\end{array}$

L. Ferrari $\cdot$ E. De Angelis $\cdot$ P. Martelli $\cdot$ P. Borghetti $(\bowtie)$

Dipartimento di Salute Animale, Università degli Studi di Parma, via del Taglio 10, 43126 Parma, Italy e-mail: paolo.borghetti@unipr.it

L. Ferrari

e-mail: luca.ferrari@unipr.it

E. De Angelis

e-mail: elena.deangelis@unipr.it

P. Martelli

e-mail: paolo.martelli@unipr.it 


$\begin{array}{ll}\text { PCVD } & \text { Porcine Circovirus Associated Disease } \\ \text { PMA } & \text { Phorbol 12-Myristate 13-Acetate } \\ \text { FITC } & \text { Fluorescein Isothiocyanate } \\ \text { MHC } & \text { Major Histocompatibility Complex } \\ \text { IL-10 } & \text { Interleukin-10 }\end{array}$

\section{Introduction}

Several techniques and parameters are used for the evaluation of immune responses in domestic animals following viral infection. Flow cytometry can be highly informative, in that it can provide information about cell subsets (phenotype) involved in anti-viral immunity and identify mediators released by these cells, such as cytokines (function).

In swine, the study of cell-mediated immune responses against viruses is considered relevant to evaluating the efficacy of vaccination protocols in stimulating antigen-specific regulatory or effector immune functions and the ability of the immune system to counteract and eliminate the pathogen by reducing the clinical signs or sustaining clinical protection. In particular, several swine viruses can differentially modulate the production of proinflammatory and immune cytokines, such as IFN $\gamma$, a cytokine orchestrating both innate and adaptive immunity (Darwich et al. 2003; Meier et al. 2003). The aim of the present study was to optimize IFN $\gamma$ intracellular staining coupled with $\mathrm{CD} 8 \alpha$ surface staining for flow cytometric analyses under physiological conditions and different virus-challenge conditions. A classical model of anti-viral immunity [Aujeszky's Disease Virus (ADV) vaccination] and vaccination or natural infection by a virus with a more complex virus-host immune system interaction [Porcine Circovirus type 2 (PCV2)] were evaluated.

\section{Materials and methods}

Blood samples were collected from pigs in the absence of disease at slaughtering (10 months of age) and analysed directly $(100 \mu \mathrm{l})$ or after peripheral blood mononuclear cell $(\mathrm{PBMC})$ isolation $\left(5 \times 10^{5}-1 \times 10^{6}\right.$ cells) using a Histopaque-1077 ${ }^{\circledR}$ density gradient. PBMCs of ADV-vaccinated pigs [glycoprotein E negative (gE-)/thymidine kinase negative (TK-) modified-live virus (MLV) vaccine; 4 weeks after the first dose, 1 and 2 weeks after the second dose] and PCV2-vaccinated pigs (Open Reading Frame 2 product inactivated vaccine), as well as unvaccinated acutely or chronically PCVD-affected pigs were analysed. Analyses were performed both on fresh and cryopreserved PBMCs.

To evaluate IFN $\gamma$ production in pigs, cells were stimulated in vitro for 4 or $24 \mathrm{~h}$ with phorbol 12-myristate 13-acetate (PMA; 25 or $5 \mathrm{ng} / \mathrm{ml})$ and ionomycin $(1 \mu \mathrm{M})$ and treated with brefeldin-A (Brefeldin-A, $10 \mu \mathrm{g} / \mathrm{ml}$ ) to inhibit cytokine secretion. Cells from ADVvaccinated pigs were stimulated with the MLV vaccine $(0.5 \mathrm{MOI})$ for 24 or $48 \mathrm{~h}$. Cells from PCV2-vaccinated or infected pigs were stimulated with a PCV2 field isolate $(0.125,0.25$, or $0.5 \mathrm{MOI}$ ) alone for 24 or $72 \mathrm{~h}$ or were subsequently treated with PMA ( 5 or $25 \mathrm{ng} / \mathrm{ml}$ ) and ionomycin $(1 \mu \mathrm{M})$. After incubation, cells were surface stained for 15 min with FITCconjugated anti-CD $8 \alpha$ antibody (76-2-11, Southern Biotech) and fixed for 15 min with Fix ${ }^{\circledR}$ solution. Fixed cells were permeabilized for 20 min with Perm ${ }^{\circledR}$ solution $\left(\right.$ Fix $^{\circledR}$ \&Perm ${ }^{\circledR}$ kit, Caltag Labs) and intracellularly stained for 15 min with Phycoerythrin-conjugated anti-IFN $\gamma$ antibody (P2G10, BD Pharmingen). Stained cells were analyzed with an Epics ${ }^{\circledR}$ XL-MCL cytometer (Beckman-Coulter). Statistical analyses were performed using the Student's and Paired Student's t-tests $(\mathrm{p}<0.05)$. 

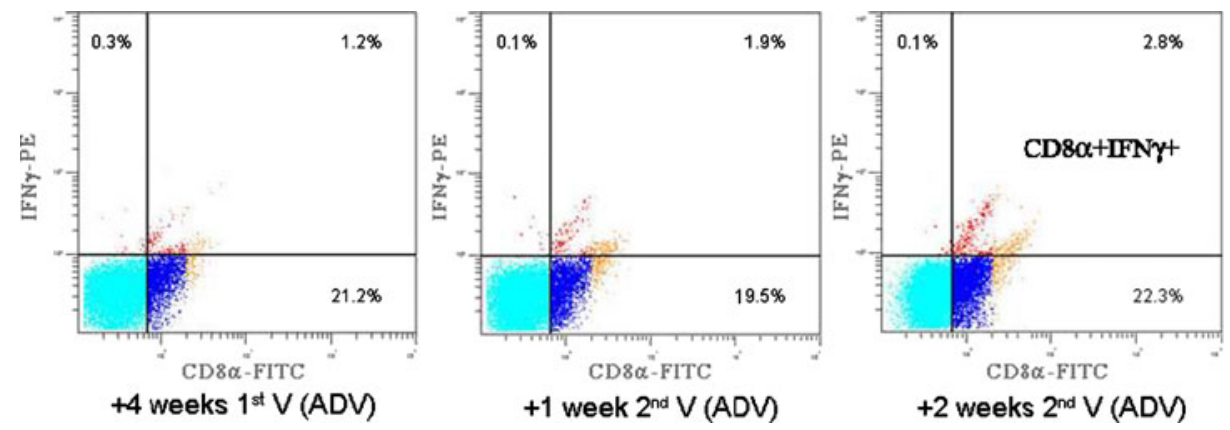

Fig. 1 Percentages of CD8 $\alpha+/ \mathrm{IFN} \gamma+$ cells in one representative ADV-vaccinated pig ( $24 \mathrm{~h}$ stimulation, 0.5 MOI MLV vaccine). V: vaccination

\section{Results}

In PBMCs of 10-month-old pigs, higher percentages of IFN $\gamma+(20.90 \pm 4.84 \%)$ and IFN $\gamma+{ }^{\text {high }}$ cells $(7.28 \pm 2.06 \%)$ were detected in comparison with those in the respective whole blood samples. No significant differences were observed in scatter profiles and fluorescence signals between fresh and cryopreserved samples (viability $\geq 99 \%$ ). A 4-h stimulation in vitro allowed for detection of IFN $\gamma$-producing cells, almost all of which were characterized by a CD $8 \alpha+$ phenotype. This IFN $\gamma+$ fraction increased $24 \mathrm{~h}$ after stimulation without indicating alterations of the scatter signals and cytotoxicity.

PMA/ionomycin was used as a positive control for in vitro stimulation with ADV and PCV2. In ADV-vaccinated pigs, ADV-specific CD $8 \alpha+/$ IFN $\gamma+$ cells were induced $24 \mathrm{~h}$ after stimulation with the MLV vaccine at an MOI of 0.5. Such double positive cells were detected 4 weeks after the first vaccination and increased 1 and 2 weeks after the booster dose. Conversely, the fraction of CD $8 \alpha+/$ IFN $\gamma$ - cells did not significantly change over time (Fig. 1). ADV vaccine stimulation for $48 \mathrm{~h}$ showed induction of much smaller IFN $\gamma+$ and $\mathrm{CD} 8 \alpha+/ \mathrm{IFN} \gamma+$ cell fractions.

Stimulation with 0.125 and $0.25 \mathrm{MOI}$ of PCV2 for $24 \mathrm{~h}$ highlighted a virus-specific fraction of $\mathrm{CD} 8 \alpha+/ \mathrm{IFN} \gamma+$ cells in both vaccinated PCVD-unaffected and unvaccinated PCVD-affected pigs (Fig. 2). Contrarily, extending the stimulation for $72 \mathrm{~h}$ induced a reduction of such a fraction. PCV2 stimulation followed by polyclonal PMA/ionomycin stimulation showed an increase of IFN $\gamma+$ and $\mathrm{CD} 8 \alpha+/ \mathrm{IFN} \gamma+$ cells in vaccinated PCVD-

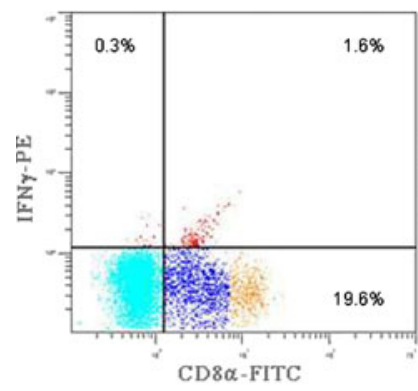

PCV2-vaccinated

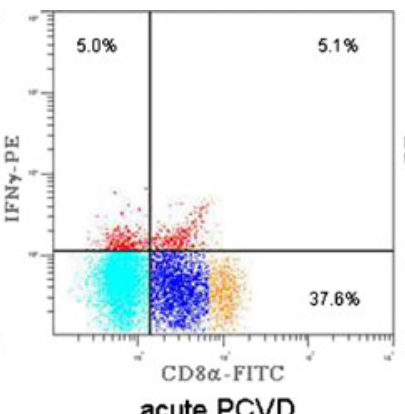

acute PCVD

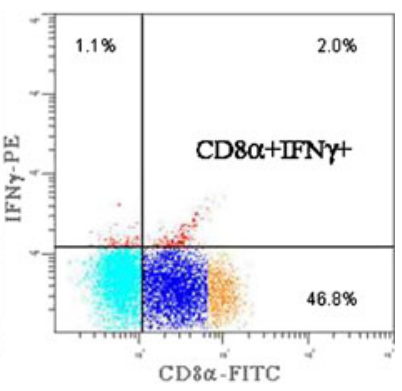

chronic PCVD

Fig. 2 Percentages of CD $8 \alpha+/ \mathrm{IFN} \gamma+$ cells in one representative vaccinated PCVD-unaffected pig and one acutely and one chronically PCVD-affected representative pig (24 h stimulation, 0.25 MOI PCV2 field isolate) 
unaffected pigs. In chronically PCVD-affected animals the IFN $\gamma+$ cell population did not increase and the $\mathrm{CD} 8 \alpha+/ \mathrm{IFN} \gamma+$ population was reduced. A variable response was detected in unvaccinated acutely PCVD-affected pigs in that some animals showed an increase in the $\mathrm{CD} 8 \alpha+/ \mathrm{IFN} \gamma+$ cell population.

\section{Discussion}

PBMC preparations allowed for optimal detection of CD $8 \alpha+/ \mathrm{IFN} \gamma+$ cells and extended in vitro incubation or cryopreservation did not significantly affect cell viability and responsiveness. PBMCs were used for the evaluation of both polyclonal (PMA-ionomycin) and virus-specific (ADV and PCV2) immune responses. A large fraction of double positive CD8 $\alpha+/ \mathrm{IFN} \gamma+$ cells were identified since multiple immune cell subsets belong to the $\mathrm{CD} 8 \alpha+$ subpopulation, including innate (natural killer cells), partially-specific ( $\gamma / \delta \mathrm{T}$ lymphocytes), and MHCrestricted (circulating memory $\mathrm{T}$ cells and cytotoxic $\mathrm{T}$ lymphocytes) cytotoxic cells.

Flow cytometry analysis in 10-month-old pigs showed levels of IFN $\gamma+$ cells in accordance with the literature (Rodriguez-Carreño et al. 2002). Regarding the virus-induced responses, 24-h stimulation allowed for identification of ADV-specific CD $8 \alpha+/ \mathrm{IFN} \gamma+$ cells, whereas a 48-h incubation reduced such cells. This reduction was probably due to a cytopathic effect (De Bruin et al. 1998). Percentages of ADV-specific IFN $\gamma+$ cells were comparable to those reported after stimulation with another herpes virus, namely Equine Herpes Virus type 1 (Paillot et al. 2005), and underline a specific and more restricted monoclonal activation. In vitro 24-h stimulation with PCV2 was a suitable condition for the identification of virus-specific $\mathrm{CD} 8 \alpha+/ \mathrm{IFN} \gamma+$ cells, whereas a $72-\mathrm{h}$ incubation reduced the response as did ADV. This was likely due to the PCV2 ability to induce and sustain IL-10 release in PBMCs and, thus dampen IFN $\gamma$ production (Kekarainen et al. 2008). The evaluation of $\mathrm{CD} 8 \alpha+/ \mathrm{IFN} \gamma+$ cell levels upon virus stimulation followed by PMA/ ionomycin polyclonal stimulation was justified since PCV2 can alter the lymphoproliferative response to mitogens and lymphocyte functions (Darwich et al. 2003). The different ex vivo responsiveness in vaccinated PCVD-unaffected, and acutely and chronically PCVDaffected pigs suggests a different cytokine modulation (Sipos et al. 2004).

Our data support the importance of IFN $\gamma$ intracellular staining and flow cytometry analysis for phenotypically identifying IFN $\gamma$-secreting cells that can also be detected by Enzyme-Linked ImmunoSpot assays. This latter technique however, despite its higher sensitivity, does not allow for discrimination of the secreting-cell phenotypes, unless cells were previously enriched by selection or depletion assays (Meier et al. 2003). Such techniques used for the evaluation of cell-mediated immunity can be optimally employed to study the efficiency of the immune response after conventional and innovative vaccine administration, as well as after natural infections.

\section{References}

Darwich L, Balasch M, Plana-Durán J, Segalés J, Domingo M, Mateu E (2003) Cytokine profiles of peripheral blood mononuclear cells from pigs with PMWS in response to mitogen, superantigen or recall viral antigens. J Gen Virol 84:3453-3457

De Bruin MG, De Visser YE, Kimman TG, Bianchi AT (1998) Time course of the porcine cellular and humoral immune responses in vivo against PRV after inoculation and challenge: significance of in vitro antigenic restimulation. Vet Immunol Immunopathol 65:75-87 
Kekarainen T, Montoya M, Dominguez J, Mateu E, Segalés J (2008) Porcine circovirus type 2 (PCV2) viral components immunomodulate recall antigen responses. Vet Immunol Immunopathol 124:41-49

Meier WA, Galeota J, Osorio FA, Husmann RJ, Schnitzlein WM, Zuckermann FA (2003) Gradual development of the IFN- $\gamma$ response of swine to PRRSV infection or vaccination. Vet Immunol Immunopathol 309:18-31

Paillot R, Daly JM, Juillard V, Minke JM, Hannant D, Kydd JH (2005) Equine IFN- $\gamma$ synthesis in lymphocytes after in vivo infection and in vitro stimulation with EHV-1. Vaccine 23:4541-4551

Rodriguez-Carreño MP, López-Fuertes L, Revilla C, Ezquerra A, Alonso F, Domínguez J (2002) Phenotypic characterization of porcine IFN- $\gamma$-producing lymphocytes by flow cytometry. J Immunol Methods 259:171-179

Sipos W, Duvigneau JC, Willheim M, Schilcher F, Hartl RT, Hofbauer G, Exel B, Pietschmann P, Schmoll F (2004) Systemic cytokine profile in feeder pigs suffering from natural PMWS as determined by semiquantitative RT-PCR and flow cytometric intracellular cytokine detection. Vet Immunol Immunopathol 99:63-71 